\title{
Implementing green practices as sustainable innovation among herbal-based SME entrepreneurs
}

\begin{abstract}
The need for policies to foster green practices, sustainable environmental management and conservation of biodiversity has been given priority by world leaders. Various factors causing environmental degradation such as global warming, pollution, climate change, deforestation and increasingly threatened biodiversity have triggered awareness among the upstream and downstream players in the manufacturing industry, providing impetus for industries to practice sustainable manufacturing and environmentally friendly management. As a result, consumers are now increasing their demand for products that are made from natural or traditional rather resources, such as herbal based pharmaceutical products, rather than chemical-based products. The sustainability issue not only places pressure on entrepreneurs to move towards green practices, but also to meet the increasing demand for herbal-based products that are produced in a sustainable environment. This article aims to assess herbal based SME entrepreneursôintention to adopt green practices in their business activities. Two hundred fifty six (256) herbal based entrepreneurs were interviewed via a structural questionnaire to gather information regarding their perception of green practices and their intention to adopt them. The Theory of Planned Behavior (TPB) was used as the theoretical framework to determine the relationships between TPB constructs. Structural equation modeling was used to analyze the information. The results indicate that positive attitudes towards sustainability are being embraced by those who are concerned about the environment and the intention to adopt innovative green practices is realized by their possession of the caring attribute.
\end{abstract}

Keyword: Green practices; Herbal-based; Intention; SMEs entrepreneur; Structural equation model 